\title{
SIMULATION-BASED PERSONNEL PLANNING FOR MATERIALS HANDLING AT A CROSS-DOCKING CENTER UNDER RETAIL DISTRIBUTION ENVIRONMENT
}

\author{
Yan Liu \\ Soemon Takakuwa \\ Graduate School of Economics and Business Administration \\ Nagoya University \\ Furo-cho, Chikusa-ku, Nagoya, Aichi, 464-8601, JAPAN
}

\begin{abstract}
This study focuses on the personnel planning of materials handling at a real cross-docking center under a retail distribution environment. Materials handling at a cross-docking center is complicated and labour intensive. Managers are usually under enormous pressure to optimize personnel planning to deal with an increasing variety of items handled by different processes. In this study, a flexible and stepwise procedure of personnel planning is proposed to minimize the total personnel expenses at a cross-docking center, especially taking merchandise mixing and operator skills into consideration. The procedure includes adopting simulation together with integer programming. In addition, the procedure is applied to an actual cross-docking center in order to confirm its effectiveness. Furthermore, the proposed method is found to be both practical and powerful to assist logistics managers in their personnel planning efforts.
\end{abstract}

\section{INTRODUCTION}

Cross-docking is a materials handling and distribution strategy by which material is consolidated and moved from receiving to shipping with a minimum dwell time in between. The primary objective of cross-docking is to eliminate storage, excessive handling, lead time, and to minimize transportation and storage costs while simultaneously maintaining the level of customer service.

In a traditional retail distribution system, for example, the distribution system might receive a single shipment of several truckloads of a given item. The shipment would be received, checked, and moved to storage. Following this, the orders would be picked from stock, assembled into shipments with other items and shipped to the stores. On the other hand, in a crossdocking operation, the incoming shipment would be unloaded, broken down and immediately reassembled in outbound shipments to the stores (Cooper, 1994). Over the past decade, cross-docking was found mainly in the retail distribution environment (Kulwiec, 1994). In today's competitive environment, cross-docking is becoming a more widely accepted distribution and warehousing method at the distribution center and has evolved especially among retail industry. At present, crossdocking has been adopted in almost all of retailing chains in Japan (Usui, 2003). As this study found, the reason for the popular use of such method is that many logistics managers realize that cross-docking can improve the flexibility and responsiveness of the supply chain network to maintain customer service levels while it is not in need of so much equipment investment than general distribution centers. However, cross-docking faces many challenges in the retail distribution environment. For example, customers are demanding such an increasing variety of items with small quantities that a large number of suppliers have to be managed and coordinated across a cross-docking center; the types of items must be handled by different processes to smooth the operations within a cross-docking center. Hence, in order to achieve increased satisfaction in service levels, cross-docking has to make frequent shipments also just in time, which result in that the high volume of items must be handled quickly in a short amount of time. In this environment, the effectiveness and efficiency of personnel planning and execution has a significant impact on the customer service and the profitability of the entire supply chain. This study aims to develop a flexible simulation-based approach to personnel planning of materials handling at a real and typical retail-cross-docking center, especially from a practical point of view.

\section{SIMULATION-BASED APPROACH FOR WAREHOUSING OPERATIONS}

Simulation has traditionally been used in warehousing operations, and it has been generally used to determine the requirements for logistics operations to allow continuous operations to provide critical support in making decisions (Kuo et al. 
2001). Zhou and Chen (2005) discussed the conceptual simulation modelling of warehousing operations commonly seen at the general merchandise distribution centers. There are many studies relating to the application of simulation to model a storage and retrieval system (AS/RS) (Harmonosky and Sadowski 1984, Medeiros, Enscore, and Smith 1986, Muller 1989, Takakuwa 1994, Takakuwa 1995, Takakuwa 1996, Burnett and Le Baron 2001, Macro and Salmi 2002, Gebennini et al. 2008). Moreover, Takakuwa et al.(2000) applied simulation models to a complicated and non-automated distribution warehouse. All the above papers demonstrated that simulation is a powerful and pragmatic tool for analyzing automated or non-automated warehouse operations.

In recent years, simulation has been a widely accepted tool in analyzing performance at cross-docking centers. Several studies have focused on various issues concerned with cross-docking centers. Rohrer (1995) described how simulation helped ensure success in cross-docking systems by determining optimal hardware configuration and software control, as well as establishing failure strategies before cross-docking problems were encountered. Magableh and Rossetti (2005) developed a simulation model of a generic cross-docking facility (CF) to examine the operational risks associated with individual CFs within a company's distribution network under a dynamic environment. At present, the review of literature indicates that no studies have been conducted regarding personnel scheduling problem at cross-docking centers using a simulation based approach. The purpose of this paper differs from previous research because a simulation based approach is developed and applied to optimize personnel planning at a typical real retail-cross-docking center.

This paper discusses a simulation-based approach to optimizing personnel planning at a cross-docking center especially taking merchandise mixing and operator skills into consideration. First, the basic description of the operations and goods flows at this cross-docking center is discussed. Then, a flexible and stepwise procedure of personnel scheduling is proposed to minimize the total personnel expenses, by performing simulation models together with integer programming. The procedure is applied to an actual cross-docking center in order to confirm its effectiveness. Finally, a special data generator is designed for a sensitivity analysis to be adapted to the change of demands. Furthermore, the proposed method is found to be both practical and powerful to assist managers in their personnel planning efforts.

\section{BASIC DESCRIPTION OF THE CROSS-DOCKING CENTER}

\subsection{Operations}

The cross-docking center of HAMAKYOREX Co. Ld under this study handles fresh and chilled foods including beverages, soft drinks, and sweet desserts. The daily personnel planning is especially critical to the cross-docking center under study where operations are ongoing 24 hours and 3 services for shipping a day, 7 days a week, and where all the items (approximately 300 items) must be received, sorted, and shipped to 236 stores across the Tokai region of Japan by a fixed time. For instance, the 1 st service is started at 0:45PM and all operating activities must be finished before 7:45PM, which is referred to "limit time for 1st service", so that all items can be shipped just in time. According to the interview with a logistics manager at the company, an average 110,000 vats (a vat is a standard container of items) of throughput were handled for each day over the past two years. Figure 1 shows the schematic operation flow at the cross-docking center. The kinds of items from multiple suppliers are received, and then sorted by two steps called the prep. sorting process and sorting process. Prep. sorting is a preceding operation and is defined as the items that are sorted by distribution zones. Following this, a sorting process is defined as items that are sorted by stores at a distribution zone.

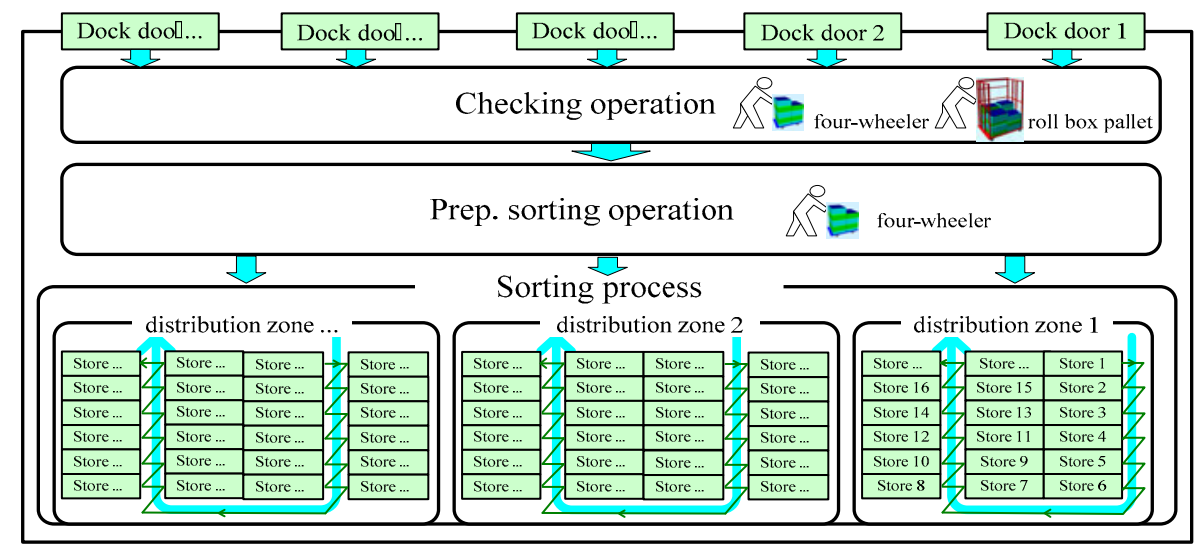

Figure 1: Operation Flow of the Cross-docking Center 


\section{Liu and Takakuwa}

Several operating rules are firmly established according to the content of products, packing materials, and inbound quantities to ensure the smooth operations at this cross-docking center. For instance, if the content of products includes beverages which are so heavy that cannot be conveyed as easily as other products, a prep. sorting process for this type products is done together with its checking process. If the packing material is cardboard, then the unpacking of cardboard is required in its prep. sorting process. Also, if the number of the inbounded quantity is small, the product requires checking and sorting at a special handling station to avoid operation confusion with other products. Hence, the general products (merchandise mix) comprises four types of products operated by different operating rules, which can be defined as: (1) beverage products; (2) returnable-packing products; (3) cardboard-packing products; (4) small-quantity-orders products. Besides the general products, as fresh products is high perishable and time sensitive goods, they are sorted by fresh products factory beforehand, and received indeed as the finally products at this cross-docking center.

For this cross-docking center, there are two operator groups. One group is assigned for checking, prep. sorting, and completion operation, or the so-called prep. sorting group. Another group is assigned as the sorting operation so-called sorting group. The cross-docking center has adopted digital sorting systems to improve the performance of the sorting group. However, the manager would like to introduce better scientific management tools and scheduling systems to reduce loads of operations and improve the performance at the preparation sorting process. This paper emphasizes the personnel planning of the prep. sorting group, especially taking into consideration the skill levels of the members of the group. The operator skills of a prep. sorting group are shown in Table 1.

Table 1: Skill Types for Operators

\begin{tabular}{lccc}
\hline \multicolumn{1}{c}{ Operations } & Type A & Type B & Type C \\
\hline Checking Operation & - & - & $\bigcirc$ \\
\hline Prep. sorting Operation & $\bigcirc$ & $\bigcirc$ & $\bigcirc$ \\
\hline Completion operation (document filing, cleaning) & - & $\bigcirc$ & $\bigcirc$ \\
\hline
\end{tabular}

\subsection{Essential Process Flows}

In this section, the essential process is identified so that the materials handling at a typical cross-docking center in the retail distribution environment can be characterised. The three essential process flows (i.e. checking operation, preparation sorting operations, and sorting operation) that are typically conducted in the retail-based cross-docking system are shown in Figure 2. Each process flow contains a sequence of activities performed by two sets of shared operator groups. All operating activities

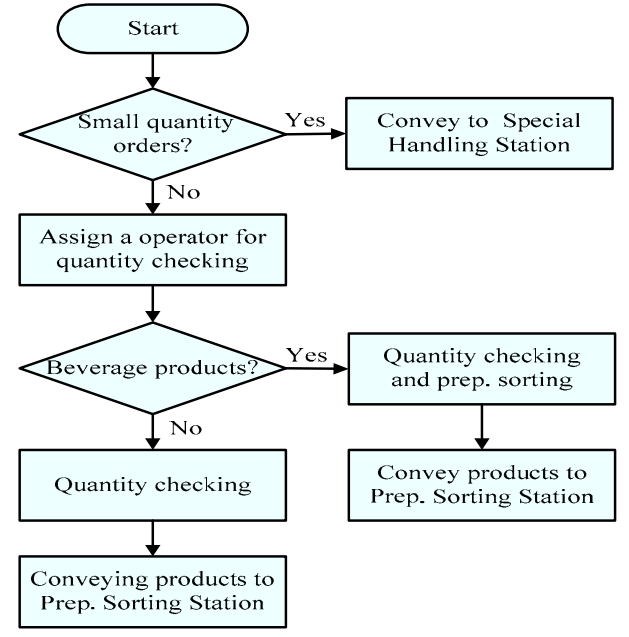

(a) Checking operation

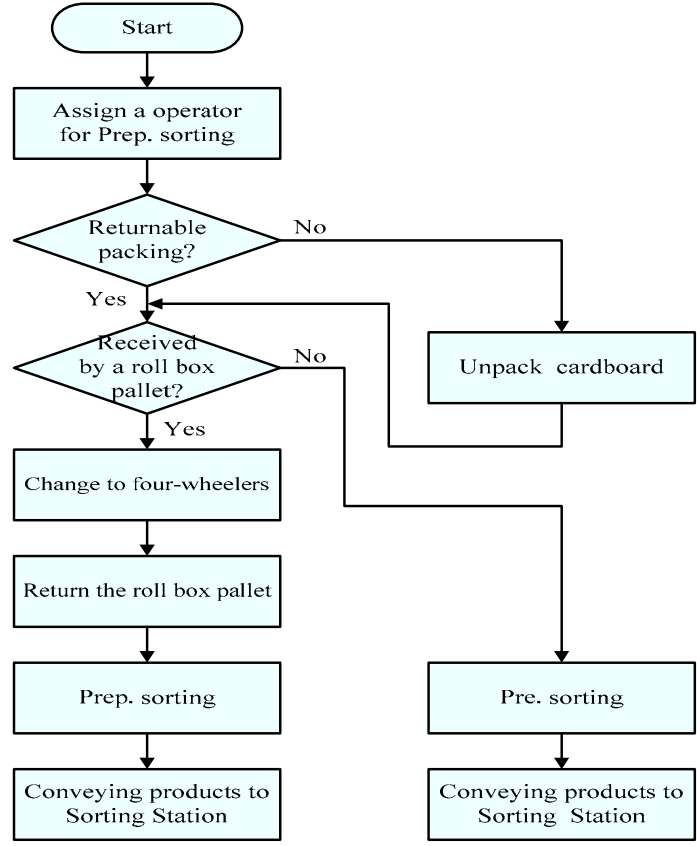

(b) Prep. sorting operation

Figure 2: Essential Process Flows

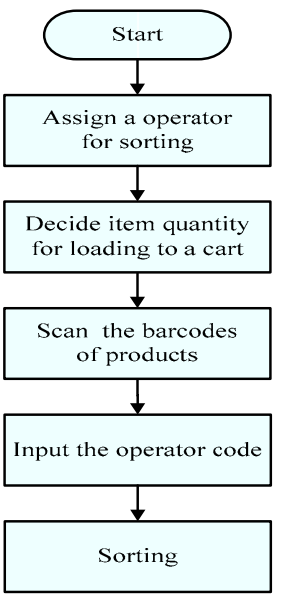

(c) Sorting operation 
must be completed by a fix time so that items for each store are shipped just in time. From Figure 2, the checking of operation begins when one item is unloaded from a inbound truck. Then an operator is assigned to count the inbound quantity and sign in for the inbound documents, called the "checking operation". Following this, the prep-sorting operation consist of two operating activities: (1) sorting by distribution zone for general merchandise, which comprises of small-quantity-ordersproduct; returnable-packing-product; cardboard-packing-product and beverage-product; and (2) pasting labels for freshproduct. In the prep--sorting-operation, the completion-operation which includes inbound document filling and clearing is also implemented. Sorting-operation consist of two operating activities: (1) Sorting by store at distribution zones; and (2) Pasting labels of each store for general merchandise.

\section{PROCEDURES TO SEEK AN OPTIMAL SOLUTION}

\subsection{Procedures}

Computer simulation is a methodology that can be used to describe, analyze and predict the performance of a complex system without the limiting assumptions. On the other hand, IP is a mathematical procedure concerned with determining the optimal allocation of scarce resources (Ignizio and Cavalier, 1994). Although a simulation can provide estimates of performance measures, and it is not usually able to provide the best schedule for operators of three skill-types. Therefore, this study adopts simulation together with IP to make use of the advantages of both techniques. The objective in this study is to minimize the total daily personnel expenses, taking merchandise mix and operator skills into consideration. The simulation model establishes the man-hour requirement of each operating activity for each work-hour, and the IP produces an optimal schedule for the operators; that is which skill-type and how many operator members is required at each work-hour. The performance measure under this study is the limit time for the 1st service. For instance, all operating activities must be completed by 7:45PM, then the target limit time for the 1 st service is denoted as 7:45PM. The target limit time must be set as an antecedent before performing the proposed procedures. As shown in the following Figure 3, the procedures to seek the optimal solution are itemized as follows:

[Step 1] Input the information of product attributes.

[Step 2] Input the order data from the retail stores.

[Step 3] Collect operator schedules submitted by individual operators.

[Step 4] Modify operator schedules by managers.

[Step 5] Build a simulation model of materials handling with the operator schedules obtained at step 4, based on the essential process flow of cross-docking demonstrated in Figure 2.

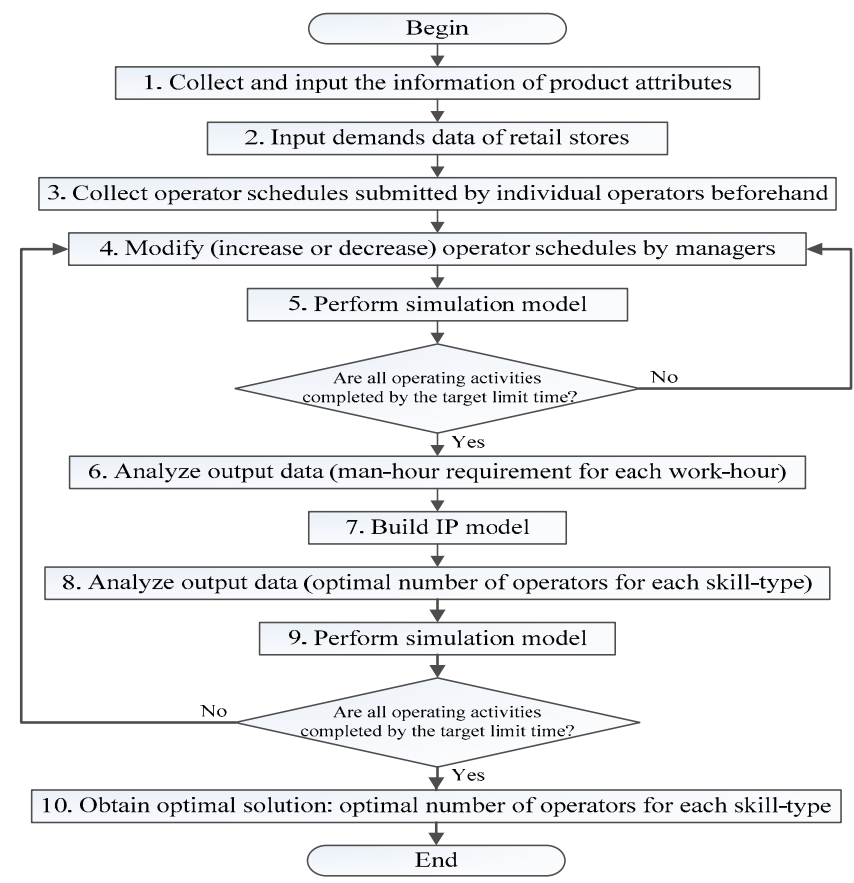

Figure 3: Proposed Procedures to Seek the Optimal Solution 


\section{Liu and Takakuwa}

[Step 6] Check animation of the simulation model to see if all operating activities for all items are completed by the target limit time. If affirmative, simulation output results are obtained such as the man-hour requirement for of the each operating activity at each work-hour, otherwise return to step 4 to increase the working time of operators.

[Step 7] Formulate IP model by using simulation output results as constraints.

[Step 8] Obtain initial optimal solution which is the number of operators for each skill-type required at each work-hour by performing an IP model.

[Step 9] Perform a simulation model to check whether all operating activities are completed by a target limit time using the initial optimal result from IP model. If not, return to step 4 to increase the working time of operators.

[Step 10] Obtain a final optimal solution by performing IP models.

\subsection{Simulation Logic}

A simulation model of materials handling for this retail-cross-docking center was created using the simulation package Arena (Kelon, Sadowski, and Sadowski 2007). Selected parts of the simulation logic at step 5 and 9 are shown in Figure 4. By performing a simulation, the man-hour requirement of each operating activity for each work-hour is outputted.

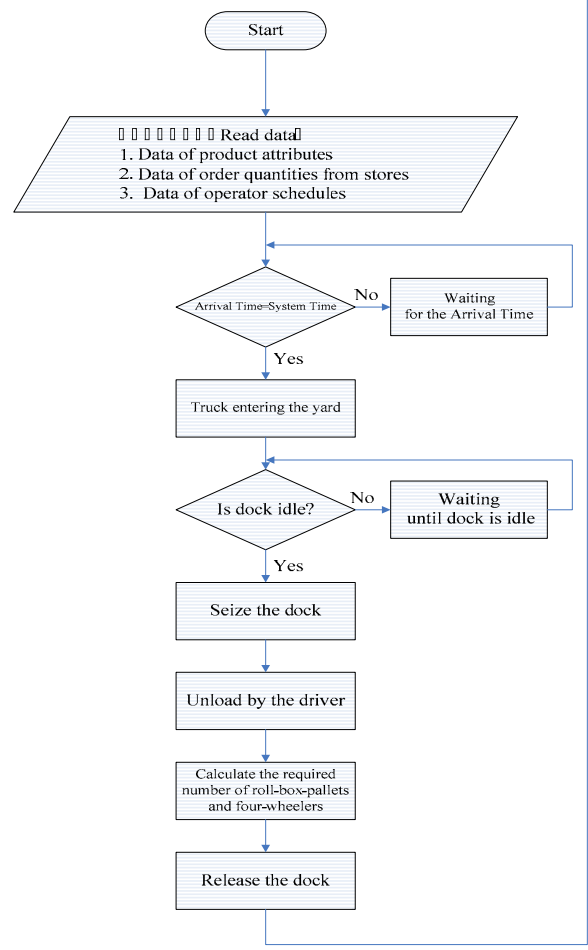

1. Data of product attributes

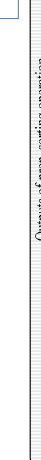

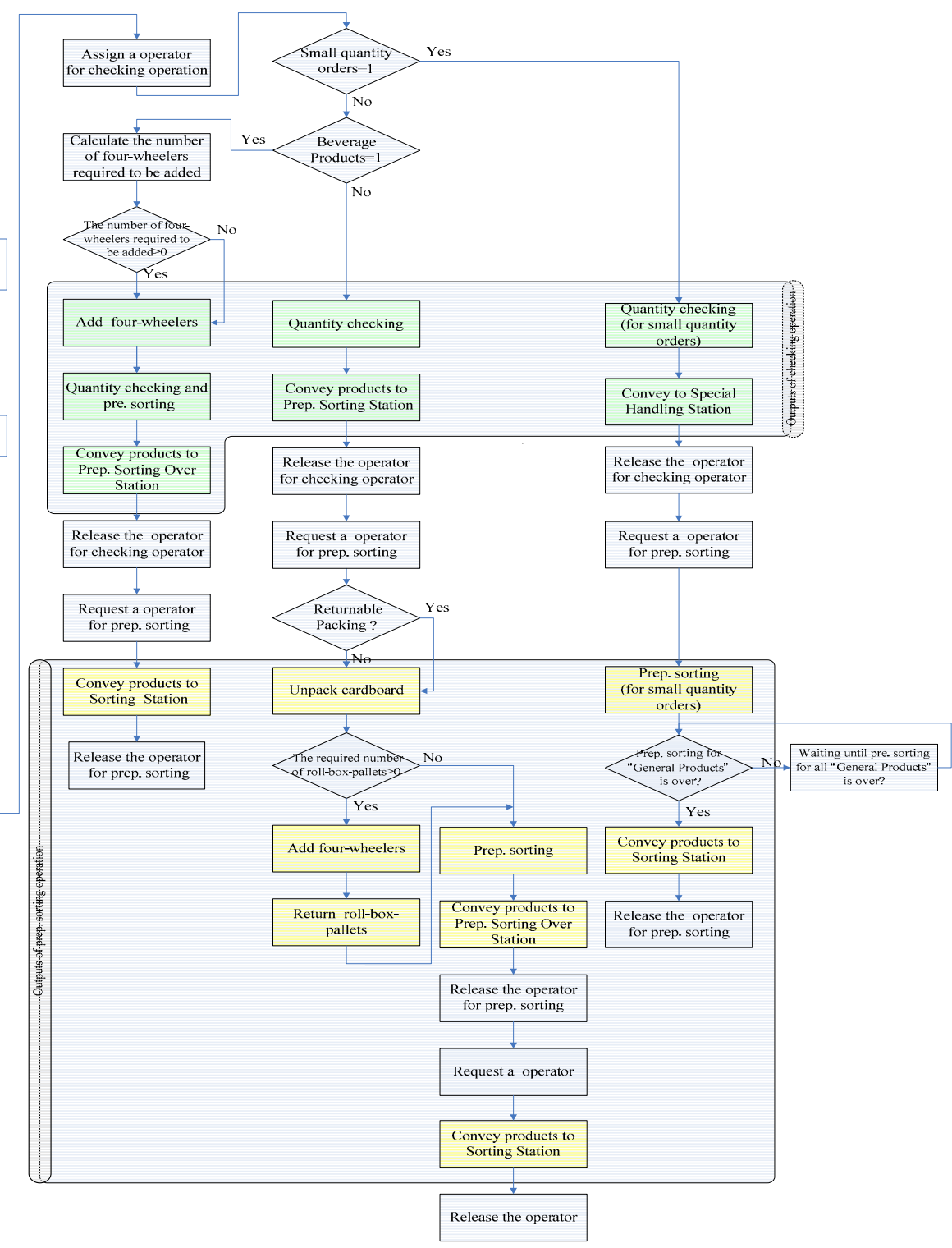

Figure 4: Selected Parts of Simulation Logic 


\subsection{Integer Programming Model}

An IP problem is a linear program in which all of the variables are restricted to integer values. The problem in this study is to determine the optimal number of operators $\left(x_{i, j, k}\right)$, taking their skills into consideration; that is, the number of operators for each skill-type required at each work-hour. The objective is to minimize the total daily personnel expenses where different types of operators do operations they can (see Table 1). Then, some assumptions considering the actual operations are necessary: (1) pasting labels for fresh products must be implemented between the 5th work-hour and 6th work-hour; and (2) completion of operation must be implemented between the 4th and 7th work-hour. By using a matrix notation, an IP model may be written as follows:

Find $x_{i, j, k}$ so as to

minimize

$$
z=\sum_{i=1}^{I} \sum_{j=1}^{J} \sum_{k=1}^{K} h_{k} x_{i j k}
$$

subject to:

$$
\begin{array}{ll}
x_{1 j 3} \geq s_{j} & (j=1, \ldots, J) \\
\sum_{k=1}^{3} x_{2 j k} \geq t_{j} & (j=1, \ldots, J) \\
\sum_{k=1}^{3} \sum_{j=5}^{6} x_{2 j k} \geq \sum_{j=5}^{j=6} t_{j}+l & \\
\sum_{k=2}^{3} \sum_{j=4}^{7} x_{3 j k} \geq c & (j=1, \ldots, J) \\
\sum_{i=1}^{I} \sum_{k=1}^{K} x_{i j k} \geq p_{\min } & (j=1, \ldots, J) \\
\sum_{i=1}^{I} \sum_{k=1}^{K} x_{i j k} \leq p_{\max } &
\end{array}
$$

where

$c=$ Man-hour of completion-operation required as determined in the simulation model (man-hour)

$h_{k}=$ Personnel expenses of a operator for one work-hour whose skill-type is $k$ (yen/hour)

$i=$ Index for operations

$I=$ maximum number of operations

$j=$ Index for work-hours

$J=$ maximum number of work-hours

$k=$ Index for skill-types

$K=$ number of skill-types

$l=$ man-hour of pasting- labels operation required as determined in the simulation model (man-hour)

$p_{\max }=$ maximum number of operators for each work-hour (person)

$p_{\min }=$ minimum number of operators for each work-hour (person)

$s_{j}=$ man-hour of checking-operation required as determined in the simulation model during work-hour $j$ (man-hour)

$t_{j}=$ man-hour of prep.-sorting-operation required as determined in the simulation model during work-hour $j$ (manhour)

decision variables:

$$
\begin{aligned}
& x_{1, j, 3:}:(j=1, \ldots, J) \\
& x_{2, j, k}:(j=1, \ldots, J ; k=1, \ldots, K) \\
& x_{3, j, k}:(j=1, \ldots, J ; k=2, \ldots, K)
\end{aligned}
$$

The constraint (2) is a constraint in which man-hour of checking-operation done by skill-type $c$ for each work-hour $j$ is required. The constraint (3) is a constraint in which man-hour of prep.-sorting-operation for each work-hour $j$ is required. The constraint (4) a constraint in which man-hour of prep-sorting-operation and pasting-labels-operation implemented at the same work-hours is required. The constraint (5) is a constraint in which man-hour of completion-operation implemented by skill-type $b$ and $c$ during work-hour $j$ is required. The constraints (6) and (7) are constraints of number of operators. With these constraints, a initial optimal solution for personnel planning can be obtained by performing IP model. 


\section{Liu and Takakuwa}

\section{APPLICATION}

\subsection{Data Collection}

A part of the selected parameters relate to the essential process flows as illustrated in Table 2 . In order to analyze the operating time of the essential process flows, we recorded all operations within the cross-docking center with a video machine for the 1 st service, 5 days. Based on the video-analysis, selection times were analyzed by using the Arena input analyzer. Then, at steps 1 and 2, the product attributes data and the actual demands data of stores were collected from the cross-docking center, which were analyzed in order to build the simulation model, as shown in Table 3 and 4. An example of actual operator schedules was collected from the logistics manager as shown in Table 5 at step 3 and 4 . The two columns colored as blue are used to set the durations spreadsheet window in Arena at step 5. Together with declared time interval number as shown in Table 6, the simulation model can be performed automatically.

Table 2: Selected Parameters

\begin{tabular}{|c|c|c|c|}
\hline & Performance & Parameters & Unit \\
\hline \multirow{4}{*}{ Checking operation } & Checking for beverage products & TRIA(0.72,1.33,1.95) & Min./Pallet \\
\hline & Checking for products with returnable or cardboard packin & $\operatorname{TRIA}(0.51,0.60,0.73)$ & Min./Pallet \\
\hline & Checking for small quantity orders & $\operatorname{TRIA}(0.19,0.20,0.25)$ & Second/Piece \\
\hline & Adding four-wheelers for beverage products & $\operatorname{TRIA}(0.22,0.27,0.32)$ & Min./Pallet \\
\hline \multirow{5}{*}{$\begin{array}{c}\text { Prep. sorting } \\
\text { operation }\end{array}$} & Unpacking cardboard & $\operatorname{TRIA}(0.23,0.93,1.86)$ & Min./Pallet \\
\hline & Prep. sorting for returnable or cardboard pcking & $\operatorname{TRIA}(1.34,2.16,3.27)$ & Min./Pallet \\
\hline & Prep. sorting for small quantity orders & $\operatorname{TRIA}(0.07,0.1,0.12)$ & Min./Piece \\
\hline & Return a roll-box-pallet & $\operatorname{TRIA}(0.44,0.56,0.78)$ & Min./Pallet \\
\hline & Take a four-wheeler & $\operatorname{TRIA}(0.43,0.47,0.55)$ & Min./Pallet \\
\hline \multirow{3}{*}{ Sorting operation } & Load to a cart & $\overline{\operatorname{TRIA}(0.20,0.50,1.00)}$ & Min./Item \\
\hline & Scan barcode of products & $\operatorname{TRIA}(0.12,0.17,0.24)$ & Min./Item \\
\hline & Sorting & $\operatorname{TRIA}(1.39,2.76,4.1)$ & Min./Piece \\
\hline
\end{tabular}

Table 3: Product Attributes

\begin{tabular}{|c|c|c|c|c|c|c|c|c|}
\hline Product code & Arrival time & Supplier code & $\begin{array}{l}\text { Small quantity orders }=1 \text {; } \\
\text { General Product }=0\end{array}$ & $\begin{array}{l}\text { Beverage Products }=1 ; \\
\text { Athers }=0\end{array}$ & $\begin{array}{l}\text { Returnable Packing }=1 ; \\
\text { Cardboard Packing }=0\end{array}$ & $\begin{array}{l}\text { Returnable } \\
\text { Container Type }\end{array}$ & $\begin{array}{l}\text { Maximum Case quantity } \\
\text { on one four-wheeler }\end{array}$ & PCS in box \\
\hline 1720044 & 1330 & 14 & 0 & 0 & 0 & - & 16 & 24 \\
\hline 1720051 & 1330 & 14 & 0 & 0 & 0 & - & 16 & 30 \\
\hline 1721317 & 1330 & 14 & 0 & 0 & 0 & - & 9 & 12 \\
\hline 1721324 & 1330 & 14 & 0 & 0 & 0 & - & 9 & 12 \\
\hline 1721331 & 1330 & 14 & 0 & 0 & 0 & - & 9 & 12 \\
\hline 1721348 & 1330 & 14 & 0 & 0 & 0 & - & 9 & 12 \\
\hline 1721409 & 1330 & 14 & 0 & 1 & 1 & 4 & 10 & 12 \\
\hline 1722215 & 1330 & 14 & 0 & 0 & 0 & - & 80 & 12 \\
\hline 1723045 & 1330 & 14 & 0 & 0 & 0 & - & 15 & 12 \\
\hline 1724257 & 1330 & 14 & 0 & 0 & 0 & - & 80 & 12 \\
\hline$:$ & $:$ & $:$ & : & : & : & : & $:$ & $:$ \\
\hline
\end{tabular}

Table 4: Demand Data of Stores

\begin{tabular}{|c|c|c|c|c|c|c|c|c|c|c|c|c|}
\hline Product code & Store 1 & Store 2 & Store 3 & Store 4 & Store 5 & Store 6 & Store 7 & Store 8 & Store 9 & Store 10 & $\ldots$ & Store 236 \\
\hline 1720044 & & 4 & & & & & & & & & $\ldots$ & \\
\hline 1721317 & 10 & 8 & 20 & 15 & 10 & 5 & & 6 & 6 & 10 & $\ldots$ & 10 \\
\hline 1721324 & & 6 & & 4 & 6 & 6 & & & & & $\ldots$ & 3 \\
\hline 1721348 & 3 & & 3 & & & & & & 3 & 3 & $\cdots$ & 3 \\
\hline 1721409 & & & & & & & 3 & & 3 & & $\ldots$ & \\
\hline 1722215 & 6 & 6 & 5 & 40 & 12 & 5 & 12 & 6 & & 10 & $\ldots$ & 6 \\
\hline
\end{tabular}

Table 5: Operator Schedules

\begin{tabular}{c|cccccc}
\hline Operator No. & Operator Name & Skill-type & Beginning Time & Finishing Time & Working Quarterhours & Working Hours \\
\hline 1 & Operator_1 & 3 & 0 & 26 & 26 & 26 \\
2 & Operator_2 & 2 & 1 & 27 & 12 & 10 \\
3 & Operator_3 & 3 & 2 & 19 & 17 & $: 50$ \\
4 & Operator_4 & 1 & 2 & $: 50$ & 4.25 \\
$:$ & $:$ & $:$ & 2 & 19 & $:$ & 17 \\
12 & Operator_12 & 2 & $:$ & & 4.25 \\
\hline
\end{tabular}

Table 6: Declared Time Interval Number

\begin{tabular}{c|cccccc}
\hline Time & $12: 45$ & $13: 00$ & $13: 15$ & $13: 30$ & $\cdots$ & $19: 45$ \\
\hline Declared Number & 0 & 1 & 2 & 3 & $\cdots$ & 28 \\
\hline
\end{tabular}




\section{Liu and Takakuwa}

\subsection{Verification and Validation of the Simulation Model}

After performing the simulation at step 5, a few methods can be used to verify and validate the model. An animation screen together with dynamic statistics and graphs provides a general view of the system operation. The animation model was constructed with Arena 3D player, as shown in Figure 5. The researchers closely examined the animation to verify whether the animation imitated the actual system. For instance, a Gantt chart of operation status by statistics in Arena was illustrated as shown in Figure 6. From this figure, the beginning and ending times of each of the items from each supplier can be compared with the actual status to verify the simulation model, which was called as "AS-IS". At step 6, the simulation results were obtained such as the man-hour of each operating activity for each work-hour, as shown in Figure 7.

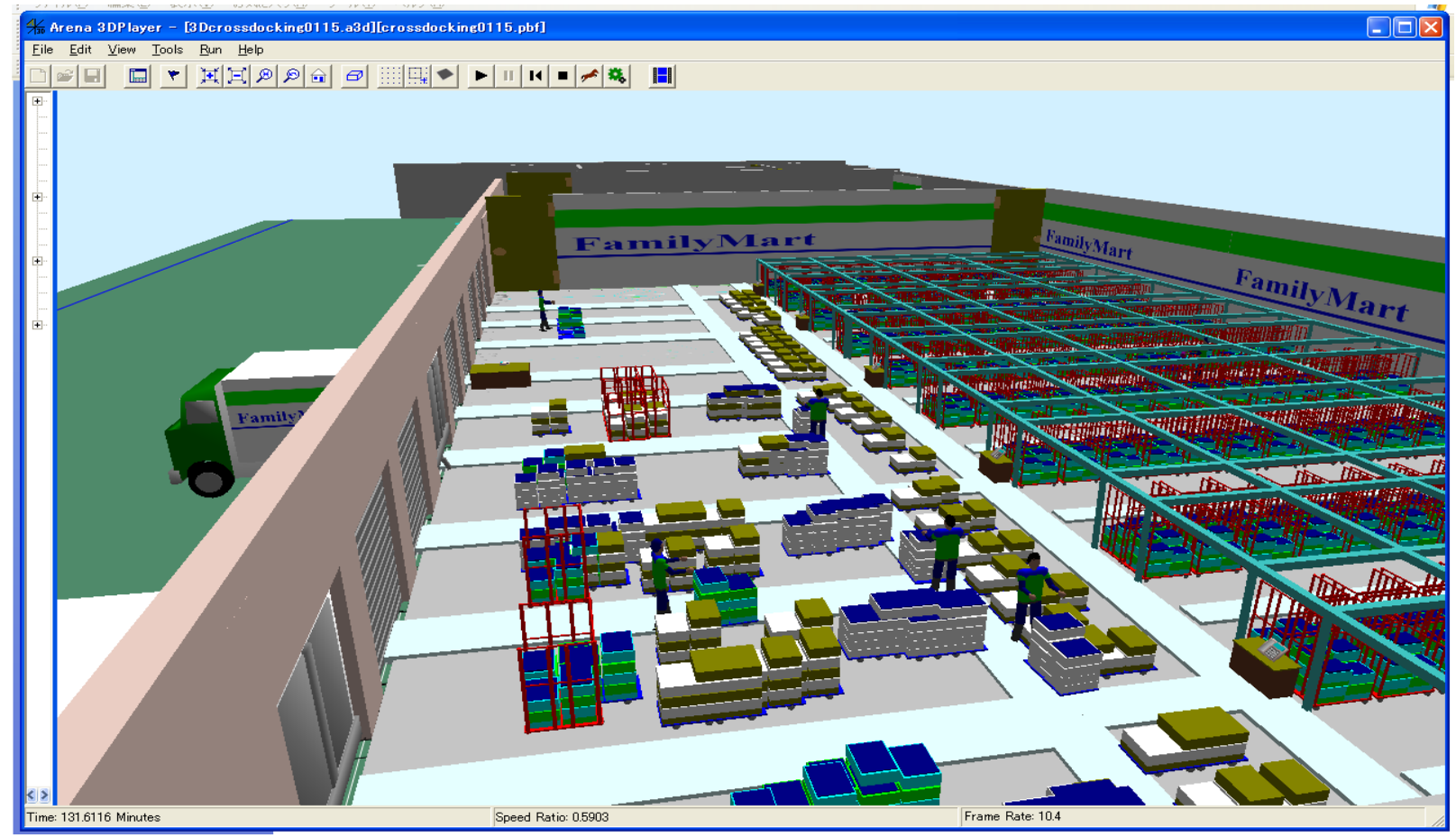

Figure 5: Part of the Animation

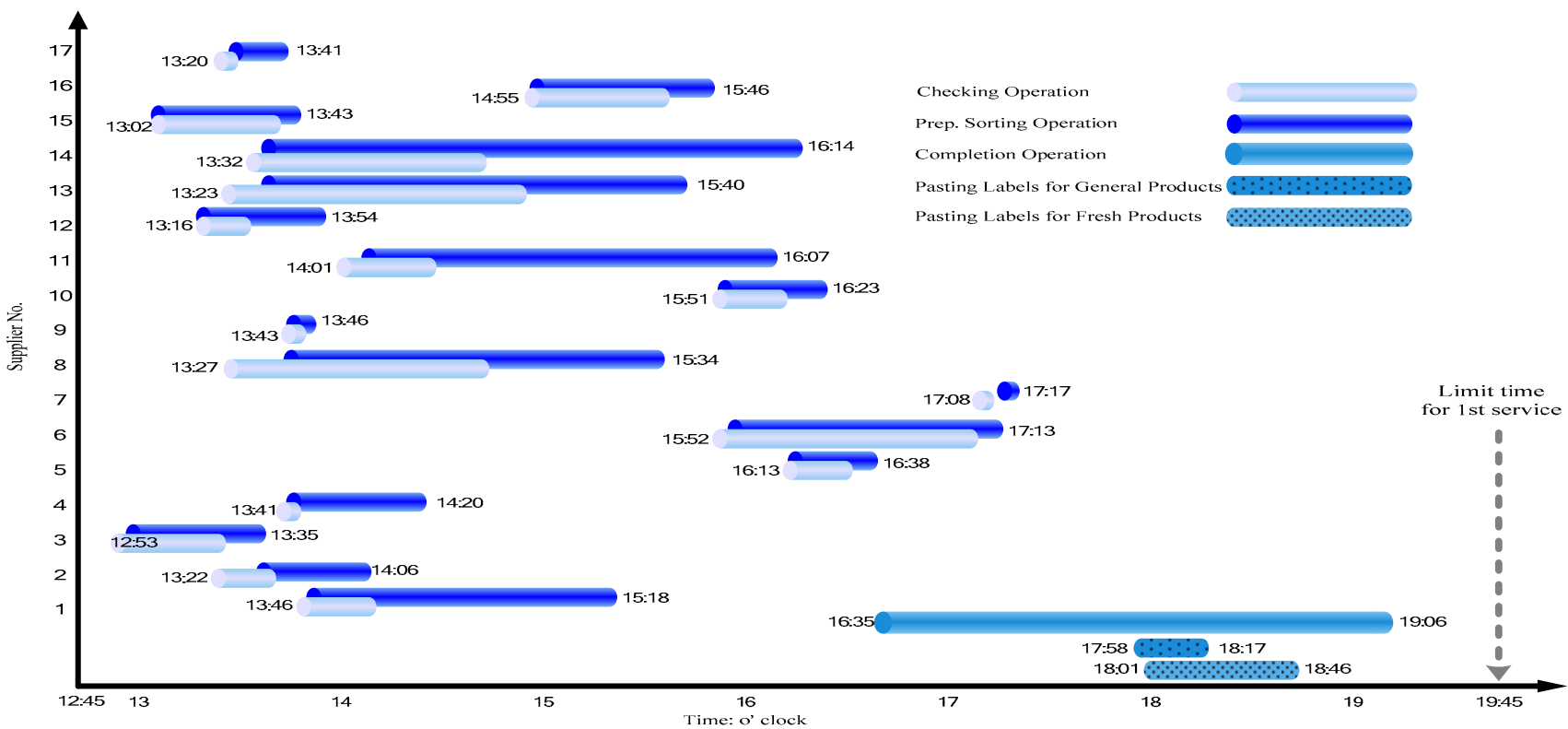

Figure 6: Operation Status (Gantt chart) 


\subsection{Integer Programming Model}

An IP model described in section 4.3 was built by using of simulation output results as constraints in order to find the optimal number of different skill-type operators needed to work for each work-hour at step 7 . In this case, the value of $c$, $l, s_{j}, t_{j}$ was obtained from the results of the simulation model. The index of skill-types $k$ (skill-type A, $k=1$; skill-type $\mathrm{B}, k=2$; skill-type $\mathrm{C}$, $k=3$ ), the index of operations $i$ (checking operation, $i=1$; prep. sorting operation, $i=2$; completion operation, $i=3$ ), the index of work-hours $j(j=1,2, \ldots, 7)$ were given predetermined. The cost of a skill-type $k$ operator for one work-hour $h_{k}\left(h_{1}=850 ; h_{2}\right.$ $\left.=900 ; h_{3}=920\right)$ was also given.

Figure 8 is an initial optimal solution obtained by performing an IP model at step 8 . Then, the initial optimal solution from the IP model is used for input data of a simulation model to check that all operations is completed by a target limit time at step 9 and 10. Therefore, the final optimal solution is called "TO-BE" and can be obtained as shown in Figure 8. According to Figure 8, the optimal solution was 5.25 man-hours less than AS-IS. The total expenses can be compared between the optimal solution (34,880 yen) and AS-IS (40,892 yen).

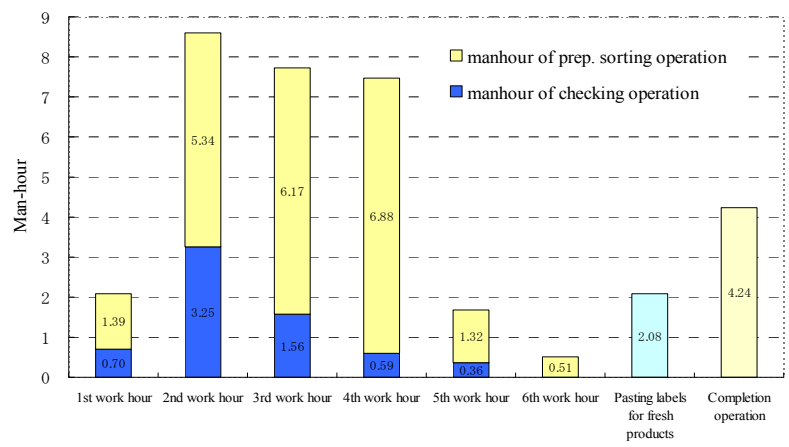

Figure 7: Man-hour Requirement from Simulation Model

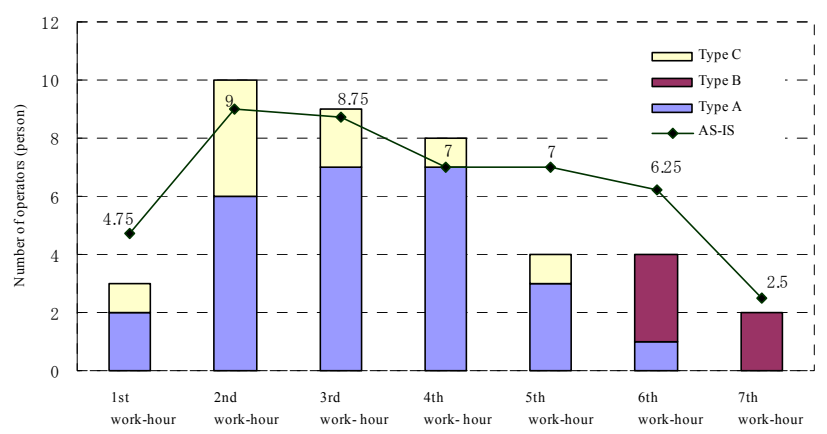

Figure 8: Optimal Solution from IP Model

\section{SENSITIVITY ANALYSIS}

\subsection{Data Generator for Simulation}

In this section, experiments are conducted so that the optimal solutions can be proposed to adapt to the change of merchandise inbound quantities. A similar idea for the data generator for simulation experiments appears in simulation of warehousing at distribution centers for creating data on in-coming and out-going trucks (Takakuwa et al. 2000). In addition, specialpurpose data-generators are designed and developed to create experimental data for simulation models especially on an international airport terminal, a call center, outpatient hospital wards (Takakuwa and Oyama 2003; Takakuwa and Okada 2005; Takakuwa and Shiozaki 2004; Takakuwa and Katagiri 2007). In this case, for the purpose of conducting experiments to adapt to the change of demands increasing by $10 \% \sim 30 \%$, a special-purpose data-generator is designed to using Visual Basic for Application (VBA) in Arena. This automates the Arena model according to user request while generating experimental data efficiently at step 5 and 9 (see Figure 3). The initial VBA user form was originally developed in this study, and the user is allowed to change the total number of merchandise pieces and the merchandise mix, as shown in Figure 9. The existing situation is illustrated in this figure that the increment rate of all merchandise is 0 percentage and the beverage products, returnable-packing products, cardboard-packing products, small-quantity-orders products account for 34.7509, 19.8388, 42.7258, and 2.6845 percentage.

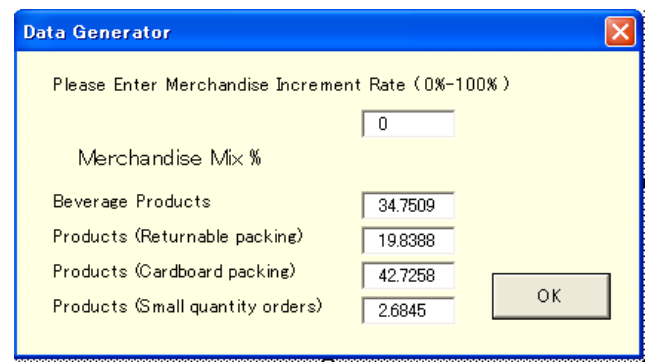

Figure 9: Data Generator User Form 


\section{Liu and Takakuwa}

At the beginning of the simulation run, the user is allowed to change the basic input parameters of the model. The required input parameters are the increment rate of all merchandise (in this case, 10\% 30\%) and the percentage of different product types handled at the cross-docking center. The generated data includes the demand quantity of every general item for each store.

\subsection{Optimal Solutions for Expected More Demands}

By making use of this generated data obtained by the data generator as an external file input for the simulation model, experiments can be conducted under any specified condition. Figures 10 and 11 show the 95\% confidence interval on man-hour requirement for checking operation and prep. sorting operation, obtained by 30 replications of a simulation model for each experiment to analyze the impact of increasing demands $(10 \% \sim 30 \%)$, based on AS-IS.

As the analytic results show, all scenarios performed well compared to the base of the section AS-IS. The peak time for checking operation appears during the 2nd work-hour, while the peak time for prep. sorting operation appears between the 2nd to 4th work-hour. Figure 12 shows the final optimal personnel planning obtained by implementing the procedure proposed in this paper for TO-BE and 10\%, 20\%, 30\% demand increasing situations. The results show that the simulation based approach is a flexible tool to help logistics managers in optimizing personnel planning, especially in dynamic and complicated circumstances.

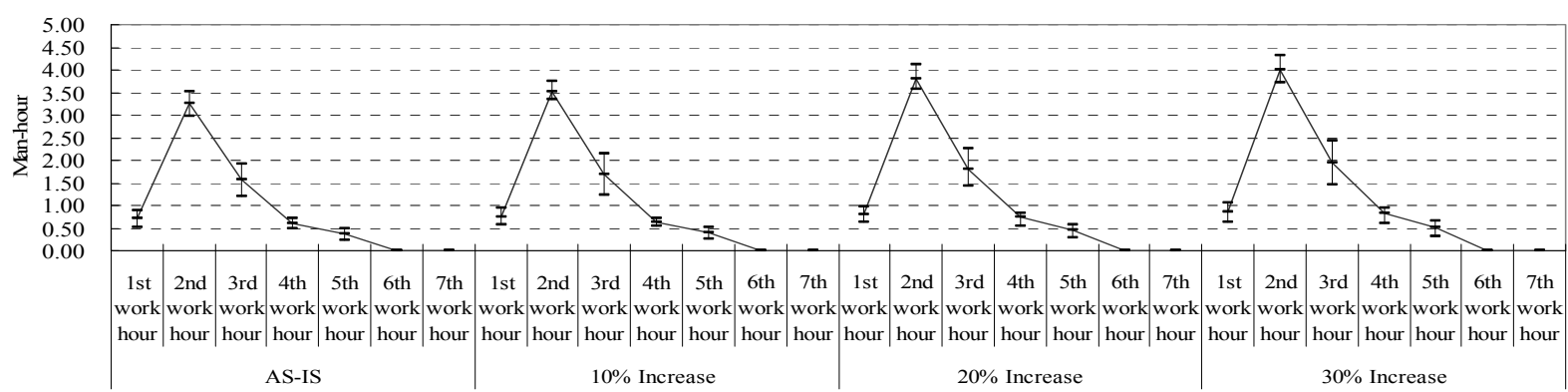

Figure 10: 95\% Confidence Interval on Man-hour for Checking Operation

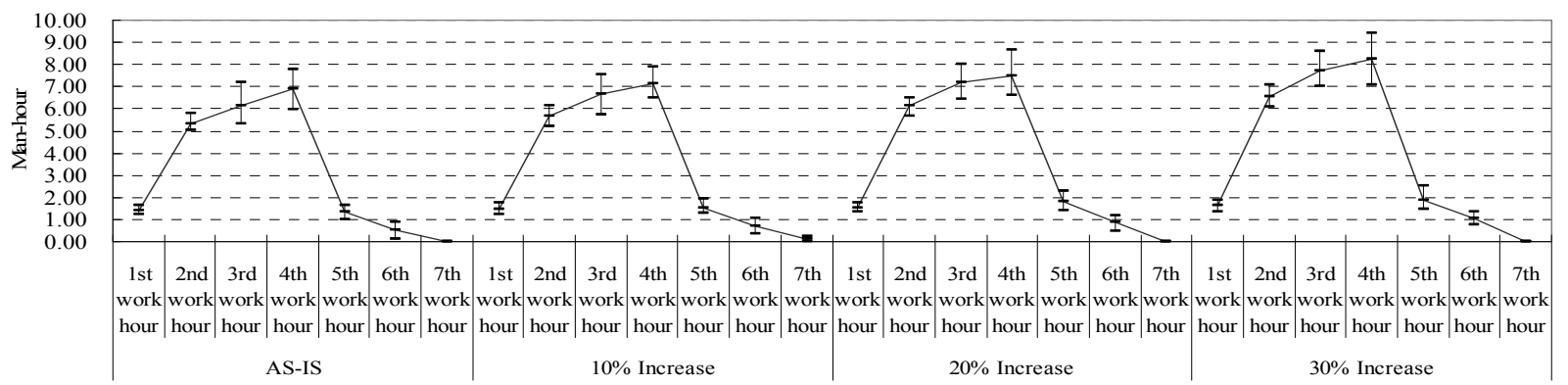

Figure 11: 95\% Confidence Interval on Man-hour for Prep. Sorting Operation

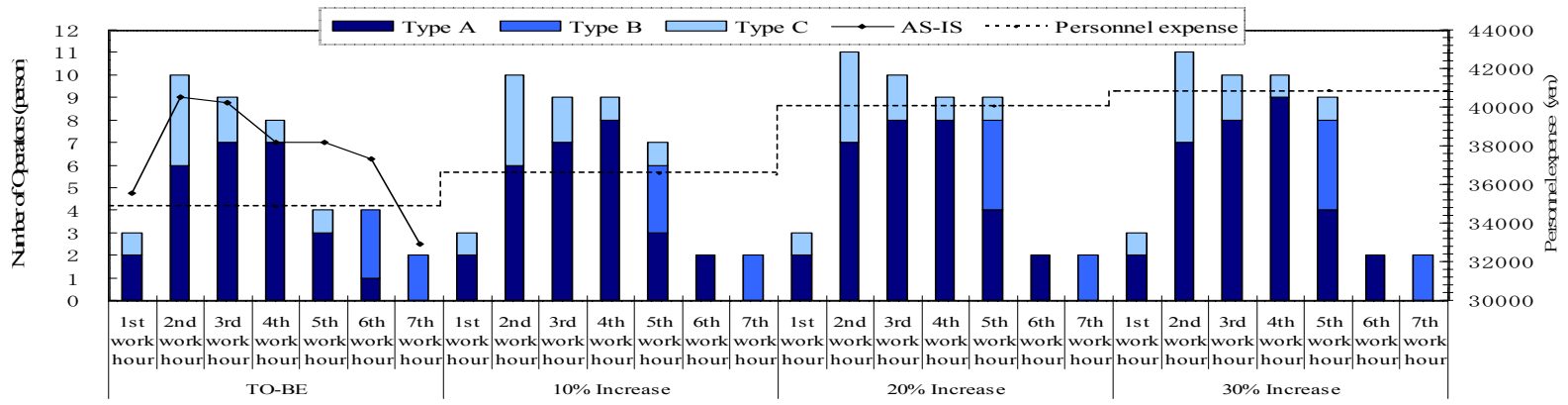

Figure 12: Optimal Personnel Planning for Increasing Demands (10\% 30\%) 


\section{CONCLUSIONS}

1. A simulation model was constructed and used to provide the man-hour requirement for operating activities for a typical cross-docking center under retail environment.

2. A flexible procedure for personnel planning was described to minimize the total personnel expenses, especially taking merchandise mixing and operator skills into consideration.

3. The proposed procedure was applied to an actual case. Materials handling at a cross-docking center was modelled through simulation in order to analyze man-hour requirements for operating activities. The results show that the optimal solution for personnel planning can be obtained easily and the proposed procedure is both practical and powerful to assist logistics managers in their personnel planning efforts.

4. As a future research, merchandise congestion will be adopted as a performance measure to analyze truck inbound scheduling and personnel planning within the cross-docking center.

\section{ACKNOWLEDGMENTS}

The authors wish to express sincere gratitude to FamilyMart Company, Ltd. and HAMAKYOREX Company, Ltd. for their cooperation in completing this research. Special thanks should be expressed to Mr. Ueda, Mr. Takahashi, and Mr. Fujita of FamilyMart Corporation, and Mr. Takasugi and Mr. Masuta of HAMAKYOREX Corporation in supporting this research effort.

\section{REFERENCES}

Burnett, D., and T. Le Baron. 2001. Efficiently modeling warehouse systems. In Proceedings of the 2001 Winter Simulation Conference, ed. B. A. Peters, J. S. Smith, D. J. Medeiros, and M. W. Rohrer, 1001-1006. Piscataway, New Jersey: Institute of Electrical and Electronics Engineers, Inc.

Cooper, J. 1994. Logistics distribution planning. 2nd ed. London: Kogan Page.

Harmonosky, C.M., and R.P. Sadowski. 1984. A simulation model and analysis: integrating AGVs with non-automated material handling. In Proceedings of the 1984 Winter Simulation Conference, 178-183. Piscataway, New Jersey: Institute of Electrical and Electronics Engineers, Inc.

Ignizio, J. P., and T. M. Cavalier. 1994. Linear programming. Englewood Cliffs, New Jersey: Prentice-Hill.

Gebennini, E., S. Dallari, A. Grassi, G. Perrica, C. Fantuzzi, and R. Gamberini. 2008. A simulation based approach for supporting automated guided vehicles (AGVs) systems design. In Proceeding of the 2008 Winter Simulation Conference, ed. S. J. Mason, R. R. Hill, L. Monch, O. Rose, T. Jefferson, J. W. Fowler, 2156-2163. Piscataway, New Jersey: Institute of Electrical and Electronics Engineers, Inc.

Kelton, W. D., R. P. Sadowski, and D. A. Sadowski. 2007. Simulation with ARENA. 4th ed. New York, NY, McGraw-Hill.

Kulwiec, R. A., ed. 1994. Retail distribution: Custom handling that goes with the flow. Modern Materials Handling 49(6): 30-33.

Kuo, S. S., E. J. Chen, P. L. Selikson, and Y. M. Lee. 2001. Modeling continuous flow with discrete event simulation. In Proceeding of the 2001 Winter Simulation Conference, ed. B. A. Peters, J. S. Smith, D. J. Medeiros, M. W. Rohrer, 1099-1103. Piscataway, New Jersey: Institute of Electrical and Electronics Engineers, Inc.

Macro, J. G., and R. E. Salmi. 2002. A simulation tool to determine warehouse efficiencies and storage allocations. In Proceedings of the 2002 Winter Simulation Conference, ed. E. Yucesan, C. H. Chen, J. L. Snowdon, and J. M. Charnes, 1001-1006. Piscataway, New Jersey: Institute of Electrical and Electronics Engineers, Inc.

Magableh, G. M., and M. Rossetti. 2005. Modeling and analysis of a general cross-docking facility. In Proceeding of the 2005 Winter Simulation Conference, ed. M. E. Kuhl, N. M. Steiger, F. B. Armstrong, and J. A. Joines, 1613-1620. Piscataway, New Jersey: Institute of Electrical and Electronics Engineers, Inc.

Medeiros, D. J., E. E. Enscore, and A. Smith. 1986. Performance analysis of miniload systems. In Proceedings of the 1986 Winter Simulation Conference, 606-612. Institute of Electrical and Electronics Engineers, Piscataway, New Jersey.

Muller, D. 1989. AS/RS and warehouse modeling. In Proceedings of the 1989 Winter Simulation Conference, 802-810. Piscataway, New Jersey: Institute of Electrical and Electronics Engineers, Inc.

Rohrer, M. 1995. Simulation and cross docking. In Proceeding of the 1995 Winter Simulation Conference, ed. C. Alexopoulos, K. Kang, W. R. Lilegdon, and D. Goldsman, 846-849. Piscataway, New Jersey: Institute of Electrical and Electronics Engineers, Inc. 
Takakuwa, S. 1994. Precise modeling and analysis of large-scale AS/RS. In Proceedings of the 1994 Winter Simulation Conference, ed. M. D. Rossetti, R. R. Hill, B. Johansson, A. Dunkin and R. G. Ingalls, 1001-1007. Piscataway, New Jersey: Institute of Electrical and Electronics Engineers, Inc.

Takakuwa, S. 1995. Flexible modeling and analysis of large-scale AS/RS-AGV systems. In Proceedings of the 1995 Winter Simulation Conference, ed. C. Alexopoulos, K. Kang, W. R. Lilegdon, and D. Goldsman, 873-880. Piscataway, New Jersey: Institute of Electrical and Electronics Engineers, Inc.

Takakuwa, S. 1996. Efficient module-based modeling for a large-scale AS/RS-AGV system. In Proceedings of the 1996 Winter Simulation Conference, 851-856. Piscataway, New Jersey: Institute of Electrical and Electronics Engineers, Inc.

Takakuwa, S. and Katagiri, D. 2007. Modeling of patient flows in a large-scale outpatient hospital ward by making use of electronic medical records. In Proceedings of the 2007 Winter Simulation Conference, ed. S. G. Henderson, B. Biller, M.-H. Hsieh, J. Shortle, J. D. Tew, and R. R. Barton, 1523-1531. Piscataway, New Jersey: Institute of Electrical and Electronics Engineers, Inc.

Takakuwa, S. and Okada, T. 2005. Simulation analysis of inbound call center of a city-gas company. In Proceedings of the 2005 Winter Simulation Conference, ed. M. E. Kuhl, N. M. Steiger, F. B. Armstrong, and J. A. Joines, 2026-2033. Piscataway, New Jersey: Institute of Electrical and Electronics Engineers, Inc.

Takakuwa, S. and Oyama, T. 2003. Simulation analysis of international-departure passenger flows in an airport terminal. In Proceeding of the 2003 Winter Simulation Conference, ed. S. Chick, P. J. Sanchez, D. Ferrin, and D. J. Morrice, 16271634. Piscataway, New Jersey: Institute of Electrical and Electronics Engineers, Inc.

Takakuwa, S. and Shiozaki, H. 2004. Functional analysis for operating emergency department of a general hospital. In Proceeding of the 2004 Winter Simulation Conference, ed. R. G. Ingalls, M. D. Rossetti, J. S. Smith, and B. A. Peters, 20032011. Piscataway, New Jersey: Institute of Electrical and Electronics Engineers, Inc.

Takakuwa, S., H. Takizawa, K. Ito, and S. Hiraoka. 2000. Simulation and analysis of non-automated distribution warehouse. In Proceeding of the 2000 Winter Simulation Conference, ed. J. A. Joines, R. R. Barton, K. Kang, and P. A. Fishwick, 1177-1184. Piscataway, New Jersey: Institute of Electrical and Electronics Engineers, Inc.

Usui, H. 2003. Latest logistics strategy of distribution centers. Current status and future prospects of food distribution centers 7-22. (in Japanese)

Zhou, M., and Z. Chen. 2005. Conceptual simulation modeling of warehousing operation. In Proceeding of the 2005 Winter Simulation Conference, ed. M. E. Kuhl, N. M. Steiger, F. B. Armstrong, and J. A. Joines, 1621-1626. Piscataway, New Jersey: Institute of Electrical and Electronics Engineers, Inc.

\section{AUTHOR BIOGRAPHIES}

YAN LIU is a Ph.D. candidate in the Graduate School of Economics and Business Administration at Nagoya University in Japan. She received her B.Sc. and M. Sc. Degrees in Economics from the HLJ Agriculture University of China in 2001 and from Nagoya university of Japan in 2006. Her research interests include demand forecast using data mining technology and simulation analysis of manufacturing and logistics systems. Her current research focuses on the optimization of logistics systems. Her email is <liu.yan@g.mbox.nagoya-u.ac.jp>

SOEMON TAKAKUWA is a Professor in the Graduate School of Economics and Business Administration at Nagoya University in Japan. He received his B. Sc. and M. Sc. degrees in industrial engineering from Nagoya Institute of Technology in 1975 and from Tokyo Institute of Technology in 1977 respectively. His Ph.D. is in industrial engineering from The Pennsylvania State University. He holds a Doctorate of Economics from Nagoya University. His research interests include optimization of manufacturing and logistics systems, management information system and simulation analysis on these systems including hospitals. He has prepared the Japanese editions of both Introduction to simulation using SIMAN and Simulation with ARENA. He has been serving concurrently as the senior staff of Department of Hospital Management Strategy and Planning at Nagoya University Hospital. His email is <takakuwa@soec.nagoya-u.ac.jp> 